\title{
MORAL Y POLITICA EXTERIOR DE ESTADOS UNIDOS EN EL MUNDO DE LA POST-GUERRA FRIA
}

\author{
Claude Pomerleau, C.S.C.
}

\begin{abstract}
El fin de la Guerra Fría ha transformado la política exterior de Estados Unidos, desafiando los valores e intereses nacionales tradicionales y causando cambios globales en diversas áreas e instituciones políticas. En el contexto de que ya no es posible distinguir entre política externa e interna, los valores subyacentes son esenciales para la formulación y aplicación de todas las políticas públicas, incluyendo la exterior. A partir de una perspectiva nacionalista y globalista, en este artículo se examinan tres áreas de la política exterior de este país, en las cuales los valores son importantes: 1 -guerra y solución de conflictos, que incluye los valores de la seguridad personal y derechos humanos. 2 - Las Naciones Unidas y las organizaciones internacionales, que incorporan los valores de la comunidad global y la solidaridad. 3-Ayuda externa y desarrollo sustentable, con los valores del desarrollo humano, la generosidad y la conmiseración.
\end{abstract}

\section{Introducción.}

Ha llegado a ser casi un lugar común postular que la Guerra Fría ha finalizado y lamentar que el sistema de la política mundial que reemplazó a ésta ha sido más desordenado y conflictivo de lo que se previó. El sistema mundial de Estados está siendo afectado por significativas transformaciones; los especialistas en relaciones internacionales están empeñados en desarrollar teorías más adecuadas para explicar estos cambios y, al mismo tiempo, proveer un marco más apropiado para la formulación de las políticas sobre la base de un núcleo de valores de aceptación general y de amplio apoyo.

El colapso del sistema de la Guerra Fría presenta un desafío urgente para clarificar las nuevas presiones y dinámicas de la política mundial. Una aproximación a este desafío podría ser el uso de la 
interpretación común de los antiguos paradigmas de la política mundial. ${ }^{1}$

Las relaciones entre naciones y de éstas con las organizaciones internacionales están transformándose significativamente. Existen nuevas implicaciones globales y locales para las políticas nacionales. El entendimiento tradicional de la relación entre política y economía, alta y baja política, y política externa y doméstica, todavía puede aportar una información útil, aun cuando este racionamiento es menos válido de lo que fue durante la Guerra Fría.

Las fuerzas que han contribuido al fin de la Guerra Fría han venido transformando la política exterior de Estados Unidos desde que la contención fuera sugerida por primera vez por George Kennan y formulada como políticas nacionales por las sucesivas administraciones norteamericanas. Estas fuerzas han causado cambios globales en las áreas del medio ambiente, mercado, sociedad, cultura y en una amplia extensión de las instituciones políticas.

Muchas de las mismas fuerzas que contribuyeron a la transformación de la Unión Soviética y Europa Central durante los ochenta están también cambiando el resto del mundo, desde la Cuenca del Pacífico a la Comunidad Atlántica. Mientras la caída del Muro de Berlín puso a prueba el poder de estas fuerzas en Europa Central y en ex-imperio soviético, las estructuras e instituciones a través del mundo también están siendo presionadas para responder y adaptarse a estas nuevas condiciones.

Este ensayo utiliza en forma intercambiable los conceptos de valores y moralidad, para dar a entender la ética y moral de la conducta humana que restringe y califica el uso del poder en todas las sociedades. ${ }^{2}$

Algunas de estas nuevas fuerzas están desafiando a los valores e intereses nacionales tradicionales ya mencionados. Ellas también incluyen preocupaciones medioambientales, crecimiento poblacional, reestructuración de la economía global, drogas y derechos humanos. Otras fuerzas consisten en movimientos religiosos, grupos étnicos, terroristas, personas marginadas e indigentes, enfermedades y plagas. Desde luego; algunas de estas fuerzas parecen ser ya familiares, mientras que otras presentan desafíos complejos e inespera-

\footnotetext{
${ }^{1}$ Karen O'Connor, Larry J. Sábato, American Government, Roots and Reform, (New York, N.Y.: Macmillan Publishing Co., 1993).

${ }^{2}$ Barry B. Hughes, Continuity and Change in World Politics, (Englewood Cliffs, N..: Prentice Hall, 1993), 2nd ed., pp. 41-42.
} 
dos. La globalización de todas éstas, crea muchos y nuevos retos tanto a los moralistas como a los especialistas y así también a aquellos responsables de las políticas domésticas y globales: En otras pảàbras, icómo deberían ser reinterpretados los valores que permitieran prosperar la vida humana bajo nuevas condiciones?

La cultura política en los Estados Unidos contiene aquellos valores asociados generalmente con las políticas públicas tanto nacionales como externas. Estas políticas incluyen valores como igualdad, libertades humanas básicas, respeto a la ley, control civil del gobierno y democracia. Ellas también contienen valores morales globalmente reconocidos tales como simpatía, honradez, obligaeión; generosidad y conmiseración. Los valores fundamentales establecen identidades nacionales y unen a los grupos y comunidades. Estos valores son también la base de la política exterior de buena vecindad hacia América Latina, si aquellas políticas están codificadas en las doctrinas Monroe o Truman y en la contención del comunismo. Ambas doctrinas fueron justificadas en términos de defender valores fundamentales y globales. Una reciente formulación de la política exterior de Estados Unidos, con implicaciones valóricas y morales, ha sido descrita como una política de "extensión" en contraste con su predecesora conocida como la política de "contención".

Cuando la política exterior era vista como desconectada de la política doméstica o remotamente relacionada con ella, fue posible concebirla como inmune a los valores que supuestamente sustentaba la política interna. Sin embargo, la creciente interdependencia de las naciones-Estados y la pérdida gradual de sus soberanías tradicionales, ha significado que ya no es más posible distinguir claramente entre política externa y nacional.

Los valores, usados en este contexto, constituyen una dimensión esencial para entender y medir el poder político; son esenciales para la formulación y aplicación de todas las políticas públicas. La perspectiva de una visión mundial comparada, utilizada en este trabajo, es la formulada por Hughes, en la cual el elemento prescriptivo de los valores representa un componente indispensable para explicar el desempeño de las fuerzas globales. ${ }^{3}$ Las políticas nacionales deberán entonces ser formuladas en el marco de las combina-

\footnotetext{
${ }^{3}$ George F. Kennan, "Morality and Forcign Policy," Foreign Affairs, Vol. 64, N22, Winter 1985-86, p. 205. Ver también Hans J. Morgenthau, Politics Among Nations, revisado por K.W. Thompson, (New York, N.Y.: Mc Graw Hill, 1993), pp. 217-250.
} 
ciones de visiones mundiales, dependiendo del contenido y objetivo de las políticas específicas.

El papel de los valores y el significado de la ética es más fácil de entender y formular en el contexto de las políticas domésticas que en la política externa. Desde la perspectiva de las primeras, el Presiden-. te Clinton y sus asesores han incluido la ética en la formulación del proyecto de ley sobre la salud pública nacional. Asimismo, la mayoría de los textos introductorios de las políticas de Estados Unidos incorporan extensas discusiones sobre el papel de los valores en los orígenes y evolución del gobierno norteamericano. ${ }^{4}$ El estudio de los valores en la política exterior es una empresa más tentativa. Mientras la mayor parte de los nacionalistas subordinan los valores a consideraciones de poder, en una perspectiva del realismo político, los globalistas han dado más importancia a elementos valóricos como comunidad y solidaridad, derechos humanos universales y paz global. 5

El realismo ha sido la visión mundial dominante en. Europa a partir del siglo diecinueve. En el ámbito de la formulación de la política exterior de Estados Unidos, éste ha sido el caso desde fines de la Segunda Guerra Mundial. ${ }^{6}$ Los realistas describen al Estado y a la competencia entre los Estados como la realidad central de la política en el sistema global. Estos actores persiguen sus intereses nacionales en un mundo de anarquía, a pesar de las organizaciones internacionales. El mantenimiento del orden dentro de este sistema llega a ser una prioridad para los realistas quienes visualizan como un bien primario la defensa del interés nacional.

Otros, sin embargo, ven al sistema global dentro de una perspectiva diferente y más complementaria en la cual las comunidades tanto locales como globales se transforman en el principal foco de análisis. Estos valores amplios, también ayudan a la configuración de la política, determinando actitudes futuras. En este contexto estamos frente a valores prescriptivos. Los globalistas e idealistas consideran a las organizaciones regionales y globales como actores esenciales de la política mundial. Tales organizaciones pueden reemplazar o complementar al Estado-nación, como así también competir y desafiar a

\footnotetext{
Mark Lindeman, William Rose y Mark Malkasian, The Role of the United States in a Changing World, (Providence, R.I.: DPG, 1993), p. 106.

${ }^{5}$ Charles W. Kegley, Jr., "The Neoidealist Moment in International Realities", Intertational Studies Quarterly, Vol. 37, N22; pp. 131-146.

${ }^{6}$ Barcy B. Hughes, op. cit. p. 49
} 
los gobiernos nacionales. Pese a que los idealistas reconocen que los Estados-naciones continúan siendo los actores internacionales mayores, no piensan, sin embargo, que éstos por sí solos sean capaces de proveer la disciplina y orden necesarios para un sistema mundial que permita, al mismo tiempo, prosperar -con relativa seguridad-a las comunidades humanas.

Los valores son más bien vagos y amorfos cuando son usados para determinar, limitar o llevar a cabo las políticas públicas.

Las excepciones se pueden encontrar en situaciones extremas, tales como violaciones masivas a los derechos humanos o la destrucción del orden social. Algunas políticas fortalecen derechos humanos específicos mientras otras socavan las preferencias políticas. Aun las elecciones económicas están influenciadas por los valores. Ultimamente, éstos pueden ser priorizados de acuerdo a los objetivos que son considerados esenciales para el contenido de la política y para la defensa de la calidad de vida. Por lo tanto, las transacciones son inevitables.

Este trabajo explora a partir de una perspectiva nacionalista y globalista tres áreas de la política exterior de Estados Unidos. En ellas, los valores juegan un rol significativo para el entendimiento de los límites y posibilidades de la acción política, como así también en la prescripción de políticas y cursos de acción apropiados. Estas áreas corresponden a las siguientes : a) Guerra y solución de conflictos; b) Naciones Unidas y organizaciones internacionales; y c) ayuda externa. En el caso de la primera, ésta incluye los valores de la seguridad personal y derechos humanos. Las Naciones Unidas y lás organizaciones internacionales incorporan los valores de la comunidad global y de la solidaridad. Finalmente, la tercera categoría incluye los valores del desarrollo humano, la generosidad y la cónmìiseración.

\section{Guerra y resolución de conflictos.}

Una consideración básica tanto para los realistas como para los globalistas es la seguridad de las comunidades nacionales $y$ la estabilidad del sistema global. Los nacionalistas, en la perspectiva del realismo, consideran a la seguridad en el marco del balance de poder de los Estados. Este equilibrio es asegurado a través de un mínimo de coaliciones que permiten beneficios máximos de acuerdo a los objetivos que persigue el interés nacional. Debido a que la seguridad 
nacionaly la mantención del sistema de Estados es el valor dominänte para los realistas, la defensa del mismo y la rectificación de su agravio legitima el uso de la fuerza para alcanzar dichos objetivos.

Los realistas justifican las guerras nacionales dentro de límites específicos. El principio de que la guerra es una extensión de la' diplomacia a través de otros medios, no es necesariamente un intento de eliminar la moral de la guerra. Más bien, es un argumento en el cual ésta debe ser juzgada por criterios políticos al igual que cualquier otra actividad política. La moral entra en esta ecuación como un esfuerzo para medir si un conflicto mantendrá o no la estabilidad y la seguridad de los Estados comprometidos, como así también la del sistema global mismo. Esto ha permitido la codificación del principio de la guerra justa. Sin embargo, el entendimiento tradicional de la guerra justa ha sido cuestionado por el poder destructivo y letal que han alcanzado las armas modernas.

Han surgido serias dudas acerca de la moralidad de la guerra moderna aun sin considerar a las armas nucleares. ¿Puede la guerra moderna ser todavía evaluada usando las condiciones clásicas de una guerrajusta? ¿En qué nivel de la formulación de unà política se sitúan las condiciones para la aplicación de la guerra justa, como las intenciones honorables, autoridad legítima, una alternativa menos violentà, alta posibilidad de éxito, más daños que bienes, o inmunidad civil? $\mathrm{El}$ alto poderío de las armas actuales hace muy difícil sino imposible diferenciar a la población civil de la combatiente. Los obispos católicos norteamericanos se refieren a-la teoría tradicional de la guerra justa cuando dicen que "bajo ninguna circunstancia pueden ser usadas las armas nucleares u otros instrumentos de destrucción masiva con el propósito de destruir centros de población u otros blancos predominantemente civiles". ${ }^{7}$

Tampoco puede ser justificada la iniciación deliberada de una guerra nuclear aunque sea limitada. ¿Existe aquí algún supuesto de que el uso defensivo de las armas nucleares podría ser justificado, aun si de ello resultaran horrores indecibles?

Mientras los obispos de Estados Unidos pensaron en la adopción de una "opción pacifista" para los individuos, como una respuesta apropiada a la capacidad de destrucción de la guerra moderna, el Papa Juan Pablo II se ha caracterizado por mantener una perspectiva

\footnotetext{
${ }^{7}$ A Pastoral Letter on War and Peace, "The Challenge of Peace: God's Promise and Our Responsen, National Conference of Bishops, Washington D.C.,1983, pp. 46-47.
} 
más tradicional a este respecto. Sin embargo, un análisis reciente de un teólogo católico acerca de la moralidad de la guerra, argumenta que la visión católica tradicional de la política global está basada en un concepto de unidad del hombre universal que trasciende cualquier poder del Estado o ideología. 8 Para muchos teólogos hoy día, como para el Papa Juan Pablo II, la defensa de los derechos humanos adquiere prioridad por sobre la defensa del Estado. Y por esta razón el Papa actual consideró que la Guerra del Golfo Pérsico no fue justificada, aun aplicando la teoría tradicional de la guerra justa. Este cambio de criterio de la seguridad nacional a los derechos individuales sugiere que la seguridad individual no puede ser garantizada solamente por los esfuerzos nacionales.

La nación-Estado, con su enfoque del poder como el principio básico del orden mundial, parece ser incapaz por si sola de establecer un orden internacional que mantenga la seguridad mundial y garantice los derechos humanos. La nación-Estado, sin embargo, ha llegado a penetrar este fenómeno cultural en el siglo XX, representando una idea cultural moderna, una innovación reciente para el ordenamiento de los grupos sociales, pero no una realidad biológica. ${ }^{9}$

Desde el momento en que otras instituciones culturales responden a las necesidades sociales, políticas y económicas, éstas desafiarán a la nación-Estado en su legitimidad.

El desorden civil y la violencia destructiva pueden resultar también de la desintegración del Estado o de grupos que tratan de capturar y controlar el poder de éste. Son los casos de la ex-Yugoslavia y de algunos Estados euroasiáticos del antiguo Imperio Soviético, como así también en las situaciones de Somalia y Sudán, Nicaragua y El Salvador. Los casos de Bosnia y Somalia, han representado opciones difíciles para los decidores de la política exterior norteamericana, no tanto en términos de valores específicos en juego, sino porque existen muchos otros conflictos civiles con manifiesta violación a los derechos humanos. Además, son opciones difíciles, debido a que el mayor bien es tomar decisiones en favor de un orden mundial estable. Estas alternativas deben ser relacionadas unas con otras y estar sustentadas en un proceso lento que mueva al mundo hacia un sistema civilizado y en que crecientemente dependa

\footnotetext{
${ }^{8}$ Kenneth Himes, "Just War, Pacifism and Humanitarian Intervention", America, Vol. 169, No4, pp. 10-15, 28-31.

${ }^{9}$ Antony Black, "Nation and Communisty in the International Order", Review of International Srudies, Vol. 19, N21, pp. 87-88.
} 
del derecho internacional, y no en el poder e intervención militar de Estados Unidos. ${ }^{10}$

Una alternativa a las crecientes luchas sobre el control y monopolio de los sistemas estatales puede ser encontrada en el aumento de la influencia de las organizaciones internacionales, especialmente en las Naciones Unidas. Esta es la única organización que puede representar al derecho internacional y a la cooperación global, en tanto conceda legitimidad a la nación-Estado. La ONU tiene mucho derecho a reclamar legitimidad en el servicio de la comunidad global, así como cualquier Estado lo hace en la comunidad local o en una feđeración de estos Estados.

\section{Las Naciones Unidas y las organizaciones internacionales.}

Los Estados Unidos deberían tener un especial interés en las Naciones Unidas debido al papel clave desempeñado por esta nación en la fundación de la Organización, como también por el rol principal jugado por este país en la formación inicial de la Liga de las Naciones. Aunque los Estados Unidos fue la únịca potencia que rehusó a ser miembro de la Liga, los diplomáticos y líderes políticos norteamericanos tuvieron una actitud muy diferente en la creación de las Naciones Unidas. Los Estados. Unidos guiaron a las Naciones Unidas en sus primeros pasos institucionales, especialmente en la formulación de uno desus rasgos distintivos como la Declaración Universal de los Derechos Humanos y en la creación de los instrumentos para una defensa global de los mismos. ${ }^{11}$

El papel de la ONU en la universalización de los derechos humanos y en la formulación del derecho internacional ha sido restringido por las mismas contradicciones que limitan el desempeño de la Organización como ente pacificador. Las Naciones Unidas defienden los valores universales y la interdependencia global, pero sus estructuras y dinámicas institucionales están basadas en el concepto difuso y absoluto de la "soberanía nạcional". El espacio para

\footnotetext{
${ }^{10}$ Pareed Zakaria, "Bosnia Explodes 3 Myths", The New York Times, 26 de septiembre de 1993, E.15.

${ }^{11}$ A. LeRoy Bennet, International Organizations, (Englewood Cliffs, N.J.: Prentice Hall, 1991), $5^{2}$ edición. Véase también, Adam Robertsy Benedict Kingsbury, United Nations, Divided World, (Oxford: Clarendon Press, 1988).
} 
ejercer liderazgo dentro del área de los derechos humanos ha sido restringido severamente por los desacuerdos sobre la naturaleza de éstos, como asimismo por el punto muerto que originan los intereses nacionales de carácter restrictivo y que son representados por pequeños grupos que monopolizan el Consejo de Seguridad.

En efecto, las Naciones Unidas encaran las mismas contradicciones que aquellas que enfrenta cada nación-Estado individualmente, como es el caso de los Estados Unidos. En otras palabras, las calificaciones para el liderazgo en la ONU y la hegemonía militar y económica son las mismas calificaciones que amenazan los valores más importantes de la comunidad humana, aquellos valores que le dan a dicha institución internacional su misión distintiva, esto es, la interdependencia material y moral.

Durante medio siglo, la historia de las relaciones de Estados Unidos con la ONU ha estado llena de contradicciones, contratiempos y conflictos. Algunos autores sostienen que esta relación ha sido consistentemente negativa y deprimente. ${ }^{12}$ A pesar de esta relación problemática, ha habido algunos momentos de apoyo entusiasta a la ONU de los líderes y opinión pública norteamericana, especialmente durante las guerras de Corea y del Golfo Pérsico. Sin embargo, durante la mayor parte del período intervencionista, Estados Unidos ha rebajado el papel de la Organización, ya sea retirando su participación en algunas instancias o bien no cumpliendo, como hasta hace poco, con sus compromisos. Quizás, el desdén y distanciamiento de los Estados Unidos hacia la ONU durante los ochenta será reemplazado en los noventa por una crítica más benevolente y una participación más positiva en esta institución internacional.

Dos temas relevantes destacaron en el discurso del Presidente Clinton en las Naciones Unidas el 27 de septiembre de 1993. El primero, es un llamado a clarificar el criterio sobre el papel pacificador de Naciones Unidas. El otro tema dice relación con el llamado a un control más efectivo de los materiales nucleares. Esta nueva relación e interés de Estados Unidos con la ONU, aunque puede ser tentativa, es de gran importancia tanto para el futuro de la Organización como para establecer criterios de control sobre armas modernas destructivas. También esta relación es útil para coordinar el

\footnotetext{
${ }^{12}$ Robert W. Gregg, The U.S.-UN Relationship: Troubled Past, Uncertain Futuren, en: Eugene R. Wittkopf, The Future of American Foreign Policy, (New York, N.Y.: St. Martin's Press, 1994), 2a edición, pp. 257-274.
} 
acceso a muchos bienes públicos que son solamente de responsabilidad de la acción colectiva, tales como la protección de la atmósfera, los bosques, los océanos, el agua potable, recursos energéticos y aun algunas categorías de derechos humanos.

La actitud general de los Estados Unidos hacia las Naciones Unidas es tan significativa como sus decisiones dentro del Consejo deSeguridad. Esta organización ha desarrollado en gran medida los instrumentos y mecanismos para promover los derechos humanos, pero su acción efectiva en la protección de éstos ha sido generalmente limitada, por no decir tímida. A este respecto, la Comisión InterAmericana de Derechos Humanos de la Organización de Estados Americanos es un ejemplo de cómo la presión externa ejercida por una organización internacional puede influir en los Estados miembros. 13

La presión de esta Comisión sobre el régimen autoritario de Chile durante los setenta y los ochenta fue un factor externo significativo en mover a esa nación hacia una transición, desde una administración militar -con amplias violaciones a los derechos humanosa una democracia civil respetuosa del derecho internacional y de los derechos humanos. Los Estados Unidos, porsu parte, podrían ejercer una más efectiva presión sobre la Comísión de Derechos Humanos de Naciones Unidas, mucho mayor que la realizada hasta ahora, con la excepción de la administración dél Presidente Carter. Debido a la naturaleza de la organización de Naciones Unidas y la participación dominante de los grandes Estados, iniciativas individuales de países claves como Estados Unidos son esenciales en el apoyo a los derechos humanos.

Los derechos humanos constituyen una controvertida área para la política exterior de Estados Unidos, pero el apoyo de organizaciones internacionales como la ONU en la formulación de una más efectiva política norteamericana en este campo, parece ser un marco más positivo y realista. Mientras que los valores económicos tales como el libre mercado y el liberalismo han sido grandes exportaciones de la política norteamericana, los valores humanos más difusos, pero no menos importantes -como las libertades políticas, económicas y sociales básicas- deberían llegar a constituir una párte gravitante de cualquier relación renovada de los Estados Unidos con la Organización de Naciones Ưnidas.

\footnotetext{
${ }^{13}$ Tom J. Farer, "The UN and Human Rights", en: Roberts y Kingsbury, op. cit, pp. 95-138.
} 
La integración regional representa una etapa intermedia importante para el reforzamiento de las organizaciones internacionales en general y la ONU en particular. Los Estados Unidos, Canadá y México han negociado un acuerdo comercial denominado Asociación Norteamericana de Libre Comercio (NAFTA), el que pronto tendrá más que características comerciales. NAFTA es un buen ejemplo de la complejidad de los cambios globales y de las sutilezas de aplicar principios morales y valores generales, como los derechos humanos, en la política exterior. Se supone que los valores presentes en este caso son la defensa del medio ambiente, democracia en México, trabajos para los Estados Unidos y el fortalecimiento de la solidaridad global. Las áreas difíciles son realmente la económica y política y no necesariamente los temas morales. Mientras que el fortalecimiento de los mercados regionales es visto por la mayoría de los economistas (no necesariamente todos) como un bien público, existe desacuerdo respecto de los efectos específicos del mercado. Esta es una materia compleja a diferencia del tema de la guerra, ya que requiere de matices para una definición limitada o amplia.

\section{Ayuda externa y desarrollo sustentable.}

El fin de la Guerra Fría ha desafiado a los Estados Unidos a reconsiderar los propósitos y fines de su programa de ayuda externa. No obstante, cualquier reformulación de ésta, debe incluir las cambiantes necesidades de Estados Unidos, como las dinámicas de transformación de una compleja comunidad global de Estados y de organizaciones internacionales. La ayuda externa compromete directamente algunos de los valores norteamericanos más definidos, especialmente aquellos relacionados con la generosidad y lealtad. Pero dicha ayuda también encierra valores que influyen en la prosperidad económica, en un medio ambiente sano y en el liderazgo mundial, para aquellos que ven a éste como un factor esencial para la seguridad nacional. La ayuda externa fue también importante para la relación de los imperios con sus colonias y para la Unión Soviética con sus países satélites.

Mientras el Plan Marshall puede ser considerado por muchos como el ejemplo más exitoso de ayuda exterior en la historia de Estados Unidos, la ayuda posterior a éste, especialmente a los países pobres, no ha tenido tanto éxito. Desde los años cincuenta, la ayuda 
externa norteamericana fue reorientada hacia los países en vías de desarrollo y fue vista como un instrumento necesario de la Guerra Fría. Como resultado de ello, los propósitos de la ayuda exterior han generado controversias y oposición a esta política. Es por lo mismo que la asistencia externa oficial norteamericana se ha reducido desde el $2 \%$ del PGB a comienzos de los cincuenta al $0.2 \%$ en la actualidad.

Las prioridades para la ayuda exterior de los Estados Unidos fueron reorientadas desde una conmiseración por las víctimas de la guerra y consolidación de las instituciones democráticas, a la estabilidad del Medio Oriente y la atracción de aliados anticomunistas. La ayuda también fue vista como una recompensa de lealtades y como instrumento para la mantención de la estabilidad regional. Por esta razón, Israel y Egipto recibieron cerca de un tercio de los 16.000 millones de dólares de la ayuda externa norteamericana en 1990.

Sin embargo, el apoyo popular a la ayuda externa declinó desde el momento en que ésta comenzó a ser más ambigua y se incrementara el resentimiento hacia los lazos que la ataban y condicionaban. De este modo, la ayuda externa se redujo desigualmente dependiendo del status que alcanzara la Guerra Fría. El monto de la ayuda externa es probable que continúe reduciéndose en los noventa, representando aproximadamente 11.000 millones de dólares en el año fiscal de $1993 .{ }^{14}$ El fin de la Guerra Fría ha incrementado el debate acerca del impacto de la ayuda externa y de los valores que explican y justifican tal ayuda. Un creciente número de especialistas están demandando un nuevo marco explicativo sobre la ayuda exter.. na. Este nuevo referente teórico debe ser justificado no sólo en términos de conmiseración para lọs necesitados, sino que deberia también ser orientado para alentar y promover el desarrollo sustentable en aquellas áreas donde las condiciones sean consideradas apropiadas. $^{15}$

El Presidente del Sub-Comité de Operaciones Externas del Senado de Estados Unidos, senador Patrick J. Leahy, quien es el responsable de elaborar y presentar el proyecto de ley anual sobre asignación de la ayuda externa, ha advertido repetidamente que sin una reforma amplia el apoyo a la ayuda continuará decreciendo en

\footnotetext{
${ }^{14}$ Hughes, op. cit, p. 104.

${ }^{15}$ James L. Clad y Roger D. Stonè, "New Mission for Foreign Aid", Foreign Affairs, Vol. 72, Ne1, pp. 196-205.
} 
tanto la opinión pública continúe oponiéndose a ésta, o llegue a ser más indiferente. ${ }^{16}$

Leahy cree que el actual programa de ayuda externa fue tanto estimulado como limitado por los éxitos del pasado. El Plan Marshall fue un factor significativo en la espectacular y rápida recuperación de Europa Occidental, reforzando con ello la creencia de que la ayuda externa es un arma indispensable en el arsenal de los Estados democráticos.

No obstante, la recuperación política e institucional de Europa no se repitió en forma general en el mundo en desarrollo, excepto en algunos pocos casos recientes en Asia y América Latina. En estas situaciones, el comercio aperece como un factor más importante que la ayuda. Por lo tanto, la ayuda externa simplemente no generó milagros en otras partes del mundo. Es más, ésta ha sido considerada como desaprovechada y los abusos en su aplicación han llegado a ser objeto de informes de investigación tan comunes como lo fueron los relativos a la ineficacia y antinorteamericanismo de los miembros de Naciones Unidas. La agencia principal en la administración de la ayuda externa de Estados Unidos, la AID, ha sido culpada en gran parte de la ineficiencia de las políticas de asistencia norteamericana, o al menos, en su mal manejo. En consecuencia, esta agencia se ha desorientado y desalentado. Su reputación se ha hundido a un nivel tan bajo, que un número creciente de críticos se han preguntado si se la debería seguir financiando. 17

Las condiciones que establece Leahy para la renovación del programa de ayuda externa están sustentadas en dos criterios:

a) ¿Sirve la ayuda externa al nuevo interés nacional de Estados Unidos en el mundo de la post-Guerra Fría?

b) ¿Promueve el programa de ayuda externa la causa de la libertad y justicia en el mundo?

El significado de estos dos criterios parece ser que debe incluir los valores en cualquiera reconsideración efectiva de la.ayuda externa, especialmente para aquella que recibe la aprobación de los ciudadanos como así también el apoyo en el congreso. ${ }^{18}$

\footnotetext{
${ }^{16}$ Senator Patrick J. Leahy (D-Vt.), Congressional Record, 103rd. Congress, 1st Session, Vol. 139 , No10.

${ }^{17}$ Senator Patrick J. Leahy, op. cit, Vol. 139, N10.

${ }^{18}$ Max Singer y Aaron Wildavsky, The Real World Order, Zones of Peace - Zones of Turmoil, (N.J.: Chatham House Publishers, Inc., 1994), p. 154.
} 
La ayuda externa a su vez representa un valor simbólico importante. Ella es un medio particularmente efectivo para responder directa y rápidamente a los desastres naturales y tragedias nacionales alrededor del mundo y con la cual los ciudadanos de Estados Unidos pueden identificarse fácilmente. El valor simbólico de esta clase de ayuda externa consiste en representar los valores colectivos de un pueblo, tales como generosidad, compromiso y preocupación. Leahy apunta a Rusia como un recipiente de la ayuda externa significativamente apropiado dentro de un esquema que responde a los intereses de seguridad y a los valores nacionales. Mientras algunos pueden argumentar que la ayuda externa puede ser mejor utilizada para programas que apoyan a las transiciones a la democracia y a las economías de mercado libre, otros insisten que la ayuda externa directa está mejor orientada a necesidades de emergencia y temporales que eviten dependencia.

\section{Conclusiones.}

Desde que la post-Guerra Fría ha llegado a ser más interdependiente y el derecho internacional un instrumento más significativo de las relaciones internacionales, los valores que sustentan la solidaridad global, los derechos humanos universales, la prosperidad económica y el medio ambiente en su totalidad, también sirven a los intereses nacionales. Mientras los valores que determinan y sustentan a las instituciones políticas no son fácilmente trasladables de una cultura a otra, éstos pueden ser fortalecidos por políticas que respeten la integridad de las instituciones nacionales, regionales y globales.

Durante la Guerra Fría, la mayor parte de los valores nacionales fueron medidos por el grado de éxito alcanzado en la oposición a la ideología y política exterior soviética. En este sentido, la defensa de los intereses nacionales y el anticomunismo coincidieron convenientemente. La creencia excepcional que el compromiso de los Estados Unidos con los derechos constitucionales, es superior al de la mayoría de los países del mundo, ha distorsionado, generalmente, el entendimiento norteamericano de los complejos problemas del desarrollo, especialmente en el Tercer Mundo. ${ }^{19}$ Con el fin de la Guerra Fría, los Estados Unidos no serán capaces de justificar, bajo el pretexto de

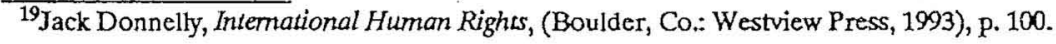


oponerse al comunismo internacional, una política destructiva de intervenciones unilaterales que con frecuencia violaron los derechos humanos. De esta forma, tanto los realistas como los globalistas deberían recibir con agrado el desarrollo de este fenómeno.

En la actualidad, los intereses nacionales de los Estados Unidos deben ser reorientados hacia el fortalecimiento de las organizaciones internacionales y las Naciones Unidas, especialmente en las áreas de los derechos humanos, defensa del medio ambiente y el desarrollo económico y social sustentable en los países en vías de desarrollo. Esta transición requerirá de liderazgo político, consistencia e imaginación por parte de la política exterior norteamericana. La alternativa aislacionismo está autoderrotada y es insostenible para los intereses nacionales de Estados Unidos. 